\title{
Transition, induction and goal achievement: first-year experiences of Hong Kong undergraduates
}

\author{
Beverley J. Webster $\cdot$ Min Yang
}

Received: 1 March 2010/Revised: 9 August 2011/Accepted: 27 August 2011 / Published online: 8 September 2011

(C) The Author(s) 2011. This article is published with open access at Springerlink.com

\begin{abstract}
Educators worldwide are faced with challenges of understanding how undergraduates are making their school-to-university transition and becoming inducted into their academic discipline. A recent study investigated Hong Kong first-year Chinese students' experiences of transition from school to university and induction into their discipline in relation to perceived course experiences, approaches to study and achievement of goals. Analysis of the survey data of this study indicates that although students reported transition difficulties, these were unrelated to perceptions of the course, approaches to study or achievement of goals. Students who reported good understanding of their discipline were those who achieved their goals, had a good course experience and adopted deeper study approaches. These findings suggested that rather than focusing mainly on tackling students' transition difficulties, efforts of promoting a positive first-year experience for Chinese university students and facilitating their goals achievement should be oriented towards constructing a facilitative learning environment.
\end{abstract}

Keywords First-year experience - Induction into the academic discipline Achievement of goals . Course experience $\cdot$ Approaches to learning

B. J. Webster

Faculty of Education, University of Hong Kong, Pokfulam, Hong Kong, SAR

e-mail: bwebster@hkucc.hku.hk

M. Yang (ه)

Centre for the Enhancement of Teaching and Learning, University of Hong Kong, Pokfulam, Hong Kong, SAR

e-mail: myangmin@hkucc.hku.hk

\section{Introduction}

Existing research (Krause, Hartley, James and McInnis 2005; Terenzini et al. 1994; Tinto 1993, 1997; Yorke and Longden 2007) in the past three decades shows that students' transition from learning at school to university learning (academic transition) and integration into the academic disciplines (academic induction) during the first year of university impacts not only on students' academic success but also on their social and personal growth. In previous studies on first-year experience, the focus has been placed largely on students' withdrawal from university as a result of low academic performance or lack of congruence with university environment. In some contexts such as Hong Kong, Japan and mainland China, even though students' persistence in higher education (retention) is not a major problem, first-year experience remains an important issue given the formative role of such experience in students' development and success. Context-specific knowledge about how first-year students' academic transition and induction into their discipline would be useful for enhancing teaching and learning in higher education.

This study aimed to explore Hong Kong Chinese firstyear students' experience of academic transition and academic induction. Using data from an institutional survey conducted at a university in Hong Kong in spring 2008, this study investigated first-year students' (2007 entrants) experiences and perceptions of academic transition and academic induction, which were explored in the light of participants' perceptions of the teaching and learning environment. The study was informed by literature on student learning and development generally (Biggs and Tang 2007; Pascarella and Terenzini 2005; Ramsden 2003) and first-year university experience specifically (Krause et al. 2005; Terenzini et al. 1994; Tinto 1993, 1997; Yorke and Longden 2007), with 
particular attention to Chinese students' learning approaches and culture (Kember and Gow 1991; Watkins and Biggs $2001 \mathrm{a}, \mathrm{b})$. The design of survey items on academic transition and academic induction was informed both by the literature and findings from focus groups on first-year experience with 2006 entrants from all faculties in the University in fall, 2007 (not reported in this paper). First-year students' perceptions of the teaching and learning context were investigated using the Course Experience Questionnaire (CEQ; Prosser and Trigwell 1999; Ramsden 1991, 2003); and students' approaches to learning were examined using the Study Process Questionnaire (Biggs 1987; Biggs, Kember and Leung 2001).

\section{Background}

This study was conducted at a time when Hong Kong's universities and schools were planning for the full implementation of the new $3+3+4$ curriculum in 2012 aimed at reducing secondary school education from 4 to 3 years and increasing undergraduate education from 3 to 4 years. The study was part of a larger research project on first-year undergraduates' experience conducted at a university in Hong Kong Special Administrative Region (HKSAR) to inform the university's curriculum reform. In the reform, issues relating to provision of support and advice for students, especially during their first year of university, require special attention because of the need for faculties and departments to get ready for a double cohort of school leavers in 2012-students graduating from secondary school after completing the 7th form (7th year of secondary school education) and those graduating from school after their 6th form (6th year of secondary school education; Finkelstein and Walker 2008).

\section{Two basic conceptions for understanding academic transition and academic induction and their implications for Chinese students}

Central to our understanding of academic transition and academic induction are two interrelated conceptions: students as active participants of their first-year experience and the construction of a facilitative learning environment for first-year students. These conceptions constituted the model for examining first-year experience in the study of McInnis and James (reviewed in McInnis 2001) and were advocated by other researchers (Asmar et al. 2000; Pitkethly and Prosser 2001; Tinto 1997). The notion of firstyear students as active participants in first-year experience suggests that students should be enabled to develop a sense of agency in shaping their undergraduate education by encouraging them to make informed decision about their learning paths. To achieve this end, the construction of a 'cultivating climate' (a facilitative learning environment) is indispensable, where teacher guidance and university demands are balanced against students' choices and collaboration with peers (McInnis 2001). This may be exemplified by first-year learning communities and classrooms where teachers employ student-centred, learning-oriented teaching and assessment approaches to foster effective and independent learning (Chan 2008; Falchikov and Boud 2007; Harvey, Drew and Smith 2006).

In the Hong Kong context, the learning culture among Chinese students creates both opportunities and obstacles for encouraging first-year university students. Existing research (Chalmers and Volet 1997; Kember 2000; Tang 1996; Watkins and Biggs 2001a) shows that students from cultures influenced by Confucian philosophy or other Asian-Pacific traditions tend to prefer collaborative learning and a respect-and-care relationship between students and the teacher. For example, Tang (1996) reported that Chinese tertiary students were able to engage in a variety of collaborative assessment tasks and that collaborative students performed better than those studying individually. Yet previous studies also indicate that Chinese students at primary and secondary school are acculturated to learn through repeated practice and memorization for higher grades and to regard their teachers as the source of authoritative knowledge (see for example Salili 2001).

The dynamic of Chinese students' learning culture should be examined in relation to such Confucian values as benevolence (compassion for one's social group and society), collectivity (prioritization of collective goals and compliance to dominant or authoritative views) and learning virtues (e.g. emphasis on effortful learning; Bond and Smith 1996; Li 2002). The influence of the current educational reform in the local context should be taken into consideration as well, which promotes the use of transformative teaching and assessment approaches (e.g. inquiry-based knowledge building; Chan 2008). In view of such dynamic, it rests on teachers and institutions to assist Chinese students' academic induction and academic transition by harnessing the favourable characteristics of the learning culture such as students' preference for peer collaboration and warm social relationships in building a facilitative learning environment, so that the less favourable characteristics such as memorization for short-term retention of learning and reliance on teachers' authority can be transformed and students' sense of agency fostered. 
Issues related to academic transition from secondary school to university

Existing studies have generally confirmed that first-year students are seriously challenged in academic transition to university, having to shift from old study habits and styles of learning to those demanded by university (Krause et al. 2005; Lam and Kwan 1999; McInnis et al. 1995; Yorke and Longden 2007). For instance, Lowe and Cook (2003) found that a third of the pre-enrolment students in their study expected teaching styles to be associated with school. Two months after enrolment, a third of the students reported struggles with academic demands, workload and the independent learning style, and $41 \%$ of them perceived their teachers less helpful than expected. Asmar et al. (2000) identified a range of first-year students' transition difficulties, which included taking greater responsibility for learning, adjusting to diverse teaching styles among teachers, coping with workload, adjusting to large class size, difficulties with the language of instruction and timetabling, and lack of feedback and tutor advice. The study of Lam and Kwan (1999) with first-year students in Hong Kong reported a similar picture.

While these transition issues might have resulted from students' general expectation of a learning environment at university similar to what they experienced at school, they might also reflect the mismatch between the learning culture at school (Watkins and Biggs 2001a) and at university. This indicates a need to assist students' development of an independent learning style early in their undergraduate career and to provide them with appropriate guidance and feedback in adapting to requirements of assessment and learning at university (Krause et al. 2005).

\section{Induction into the academic discipline and the variation in students' perceptions of their learning situation}

Existing studies on academic induction have primarily focused on orientation programmes and study skills workshops (Pitkethly and Prosser 2001), but have paid less attention to students' socialization into their academic field (i.e. acquisition of the academic discourse, key concepts and tenets, and methods of inquiry of the discipline; Ratcliff 1997; Stark and Lattuca 1996). Research evidence on students' learning approaches and outcomes in and across disciplines is useful in this regard (Biggs and Tang 2007; Entwistle and Trait 1995; Gow and Kember 1990; Prosser and Trigwell 1999; Ramsden 2003). Commonly used methods in this line of research include questionnaires (e.g. the Study Process Questionnaire and the Course Experience Questionnaire, see the following section) and semi-structured interviews (Biggs 1987; Kember and Gow 1991; Ramsden 1991; Watkins and Biggs 2001b).
Researchers following this tradition have identified three different approaches to learning and shown a close relationship between approaches to learning and the quality of learning outcomes (Biggs 1987; Biggs et al. 2001; Prosser and Trigwell 1999). Students with intrinsic interest in learning tasks are likely to adopt a deep approach, seeking integrated understanding of learning materials. Students with an extrinsic motivation tend to limit effort by aggregating disconnected information from learning materials. A further approach is the achieving approach, usually used by students with the intention of maximizing grades through optimal organization of time and space. Significantly, approaches to learning have also been found to be related to students' perception of the teaching and learning context (Biggs and Tang 2007; Prosser and Trigwell 1999). Learners who prefer the deep approach are more often found in situations where the academics are perceived to show a genuine interest in students' work and adopt teaching styles that encourage critical thinking and discussion and where the curriculum is perceived to allow students room to explore academic interests (Gow and Kember 1990). Conversely, surface approach is reinforced when students perceive a heavy workload, unclear academic goals, crammed course contents, inadequate feedback and teaching/assessment strategies that demand quantitative learning outcomes. Biggs and associates (2001) observed that because the achieving approach might be aligned with the deep or surface approach depending on the perception of curricular requirements, the role of the achieving approach in indicating the quality of a teaching and learning environment might not be as clear as the deep and surface approaches.

\section{The course experience questionnaire and study process questionnaire for exploring first-year students' perception of the learning context and learning approaches}

There have been an increasing number of surveys on student perceptions of university learning environments. In common place in countries such as Australia and the United Kingdom, such surveys have been conducted for reasons of either accountability or teaching improvement or sometimes both. The Course Experience Questionnaire (CEQ) has been widely used in such surveys to provide information on the quality of teaching and learning at the degree level in order to inform the development of teaching and assessment strategies that enhance student learning outcomes (Prosser and Trigwell 1999; Ramsden 1991, 2003). For example, the Australian government has been using CEQ data to assess the performance of and plan for the needs of its universities; most Australian universities use their institutional CEQ scores for internal purposes. 
The CEQ has been integrated in a number of studies on first-year experience in Australia and UK (McInnis, Griffin, James and Coates 2001; McInnis et al. 1995).

As instrument derived from the student learning framework (Ginns et al. 2007), the CEQ investigates students' perception on the quality of teaching, clarity of goals and standards of courses, appropriateness of workload, appropriateness of assessment, and overall satisfaction with experience in the degree programme. Findings obtained with the CEQ indicated that students who employed a deep approach to study also perceived that the teaching was good, the goals and standards were clear and that independence in learning was emphasized; whereas students who adopted a surface approach perceived that workload was too high and that assessment was inappropriate (Prosser and Trigwell 1999; Ramsden 2003).

The CEQ shares a similar conceptual basis to the Study Process Questionnaire (SPQ), which investigates students' approaches to study at course or degree level (Biggs 1987; Biggs et al. 2001; Biggs and Tang 2007). The conceptual basis for the SPQ can be represented by the 3P model (Presage, Process and Product) developed by Biggs (see Biggs 1987; Biggs et al. 2001) to describe the environment in which a learning event takes place. In the model, the student-related factors (Presage, i.e. students' prior knowledge, abilities and preferred learning approaches) and teaching-related factors (Process, i.e. the teaching content, teaching-assessment methods and overall institutional climate and procedures) interact with each other to determine the ongoing approach to the task at hand, which in turn directly influences the learning outcome (Product).

There have been some reservations against using CEQ data alone as quality indicator of undergraduate education (Coates 2005). One reservation is that information on teaching alone is significant but still insufficient index on quality of education, since it is ultimately what students do in tackling learning problems and what outcomes they achieve that most directly demonstrate the quality of education. Another major limitation of CEQ is that it focuses exclusively on students' formal classroom learning, while disregarding informal out-of-class learning and experiences which has great impact on student development according a substantial number of studies (Astin 1993; Kember et al. 2001; Pascarella and Terenzini 2005). Given these limitations of CEQ, it would be helpful to use the CEQ in combination with the SPQ to provide more balanced information on the quality of student learning in the degree programme (Crawford, Gordon, Nicholas and Prosser 1998). Both questionnaires have been validated in a variety of contexts (Ginns et al. 2007; Prosser and Trigwell 1999; Ramsden 1991). The SPQ in particular has been tested with school and university students in Hong Kong, mainland China and other non-Western students (Biggs 1987; Biggs et al. 2001; Davies, Sivan and Kember 1994; Zhang and Watkins 2001).

\section{Aims of study}

The aims of this study were to investigate the first-year experience of Hong Kong Chinese undergraduates in relation to transitional difficulties, induction into the discipline and achievement of goals. Previous studies have looked at the course experience and approaches to study. Thus, in this paper, we discussed specifically the issues of transition for first-year students, their course experiences and approaches to study. We focused on the following four research questions:

1. How did first-year students perceive their transition from secondary to university in relation to issues of teaching and learning?

2. Can we demonstrate with these data a three-factor construct of transition, induction and goals?

3. How did students' perceptions of transition, understanding of the discipline area and achievement of goals relate to course experiences and approaches to learning?

4. How did student's perceptions of transition relate to understanding of the discipline and achievement of goals?

\section{Methodology}

This study involved a self-administered survey to 2007 entrants from 10 faculties at the end of their first year of study (late spring 2008). The survey was first piloted with a sample of 200 students (2006 entrants) at the beginning of their second year of study (early winter 2007). Based on feedback from that pilot, some modifications were made in relation to wording of items, length of survey and information provided in the survey. The final survey was made available online for students to complete which achieved a $10 \%$ response rate from the total first-year population. Subsequently, paper-based surveys were distributed to students during class time in their final week of semester, attaining a response rate of $46 \%$. The sample included 617 women $(56.5 \%)$ and 475 men $(43.5 \%)$. Cantonese was the first language spoken for most, but not all, of the respondents. Ethical approval and student consent were obtained prior to conducting the survey.

The survey included seven sections of which not all are discussed in this paper.

1. Background information (e.g. gender, faculty, major area of study and first language); 
2. Development of graduate abilities previously identified by the university under investigation (e.g. intellectual inquiry, leadership, communication);

3. Course experience using 17 items from the Course Experience Questionnaire (e.g. good teaching, clear goals, appropriate assessment);

4. Usual ways of studying using 14 items from the Study Process Questionnaire (deep strategies, surface strategies);

5. Transition from secondary school to university (e.g. differences in approach to teaching, mode of learning, types of assessments);

6. Induction into the discipline (e.g. understanding of the relationships between courses, key concepts and theories, employment and research opportunities);

7. General aspects of first-year experience (e.g. achievement of academic and personal goals, interactions with teachers and peers).

This paper focused on such areas as transition from secondary to university, induction into the discipline, achievement of academic and personal goals, approaches to study and perception of course experiences. Since details of the items within the CEQ and the SPQ have been reported generously in existing publications, we concentrated on reporting new dimensions of first-year experience examined in this study.

\section{Analysis}

Factor analysis was conducted with the 17 items from the CEQ and 14 items from the SPQ to confirm the structure of the four CEQ scales (good teaching, clear goals and standards, appropriate assessment and appropriate workload) and the two SPQ scales (deep and surface approaches) with this new sample. This was followed by reliability analysis. The results were not included in this paper, because they were not part of the intended research questions. The four-factor structure of the CEQ explained 55\% of the overall variance, and reliability estimates ranged from 0.575 for the appropriate workload scale to 0.832 for the good teaching scale. The two-factor structure of the SPQ explained $40.47 \%$ of the total variance. The reliabilities were 0.667 for the surface approach scale and 0.767 for the deep approach scale.

Descriptions of student perceptions of transition issues related to teaching and learning were provided to answer research question 1 . The items on perceptions of transition, induction into the discipline and achievement of goals were developed as part of this particular study. To address research question 2, exploratory factor analyses were conducted, modifications were made on the basis of these estimates, a final simple structure was identified, and reliability estimates produced. Correlation analysis was conducted to answer research questions 3 and 4 .

\section{Results}

For transition issues relating to teaching and learning, participants responded on a 5 point scale of agreement (strongly agree, agree, not applicable, disagree and strongly disagree). More than $50 \%$ of all respondents agreed that the transition issues caused them difficulties in studying at university during their first year (Table 1). The percentage of students who identified the existence of transition issues but disagreed that such issues caused them any difficulty was between $10.1 \%$ (the amount of information to cope with and the required mode of learning) and $16.4 \%$ (having different classmates in different courses). A considerable number of students indicated they strongly agreed with having experienced difficulties in managing their time (18.4\%). Less than $4 \%$ of students responded 'not applicable' to any of the items, which indicated they did not experience noticeable differences between studying at secondary and at university with respect to the transition issues.

The pool of first-year experience items was reduced from 52 to 18 based on results of the exploratory factor analysis conducted in SPSS and qualitative investigations into the student understanding of such items. Items that were correlated more than 0.8 with other items indicated multicollinearity and were removed (e.g. relationship and interaction with teachers, required class participation). Some items loaded on several factors and so were deemed to be non-discriminatory with this sample and were also removed (e.g. skills necessary for studying in my programme of study, what is needed to fulfil the programme requirements). A clear three-factor structure was identified with the 20 items which remained and these explained $56.17 \%$ of the variance (see Table 2). These factors were named transition (issues to do with the difficulties caused by perceived differences between secondary and tertiary), induction into discipline (issues to do with students'

Table 1 Percentage of agreement that transition differences cause difficulties in first year

\begin{tabular}{lll}
\hline Item of transition & $\%$ Strongly agree & $\%$ Agree \\
\hline The approach to teaching & 13.5 & 44.4 \\
$\begin{array}{l}\text { Amount of information } \\
\text { to cope with in their studies }\end{array}$ & 13.5 & 41.6 \\
The mode of learning & 12.4 & 42.0 \\
Types of assignments & 10.5 & 46.3 \\
Types of assessments & 9.4 & 41.8 \\
Level of difficulty of the & 12.0 & 41.6 \\
$\quad$ course content & & 37.3 \\
Having different classmates & 13.7 & \\
$\quad$ in different courses & & 38.9 \\
The need to manage time & 18.4 & \\
\hline
\end{tabular}


Table 2 Factor analysis of first-year experience

\begin{tabular}{|c|c|c|c|}
\hline Scales & 1 & 2 & 3 \\
\hline 1. Transition & $\begin{array}{l}0.714 \\
0.693 \\
0.675 \\
0.780 \\
0.718 \\
0.762 \\
0.683 \\
0.691\end{array}$ & & \\
\hline 2. Induction & & $\begin{array}{l}0.725 \\
0.760 \\
0.779 \\
0.753 \\
0.678\end{array}$ & \\
\hline 3. Goals & & & $\begin{array}{l}0.828 \\
0.761 \\
0.643 \\
0.621 \\
0.718\end{array}$ \\
\hline Eigen values & 5.20 & 3.51 & 1.39 \\
\hline $\begin{array}{l}\% \text { Variance } \\
\alpha\end{array}$ & $\begin{array}{c}28.91 \\
0.863\end{array}$ & $\begin{array}{c}19.52 \\
0.833\end{array}$ & $\begin{array}{l}7.74 \\
0.814\end{array}$ \\
\hline
\end{tabular}

Factor loadings below 0.5 are not reported

perception of their understanding of their area of study) and goals (students' perception of achieving personal and academic goals and fitting into the university). The internal consistency estimates were good, with all reliabilities being above 0.8 (Table 2).

Items in the three dimensions of transition, induction and goals are presented below.

\section{Transition}

Students were asked to rate their agreement to the following items as to whether the possible differences between secondary school and university education caused them any difficulty in their first year of study. Students could choose 'not applicable' if they felt there were no differences.

- The approach to teaching (lectures, tutorials, problembased learning, etc.)

- Amount of information to cope with in their studies

- The mode of learning (learning in groups, self-study, etc.)

- Types of assignments

- Types of assessments (exams, grade bearing assignments and/or quizzes etc.)

- Level of difficulty of the course content

- Having different classmates in different courses

- The need to manage time
Induction

Students were asked to rate their level of understanding of the following items related to their disciplinary area.

- The discipline I choose to study

- The content studied in the first year of my degree curriculum

- The key concepts/theories in my area of study

- How my first-year studies relate to the overall program

- Skill/qualities that will be required in my profession workplace

Goals

Students were asked to indicate their level of agreement with the following statements

- I have achieved my personal goals

- I have fitted into university life well

- My first-year experience has opened up an exciting future for me

- I am satisfied with the programme area of study that I have chosen

- I have achieved my academic goals

The correlation estimates between student perception of the difficulties of transition and the course experience showed that students who perceived the transition to be difficult also experienced the workload as being too high $(r=-0.262$, $p=0.000)$ and adopted both deep $(r=0.124, p=0.000)$ and surface $(r=0.124, p=0.000)$ approaches to learning (Table 3). However, although these results were statistically significant, the effect sizes of the relationships were small (less than 0.3). There were significant and substantive relationships between students' understanding of the discipline (induction) and their perceptions of good teaching $(r=0.381, p=0.000)$ as well as perceptions that they had clear goals and standards $(r=0.387, p=0.000)$. The relationship between students' understanding of the discipline was also significantly and substantively related to deep approaches to study $(r=0.309$, $p=0.000$ ), suggesting that students who adopted deeper approaches to study also indicated a better understanding of their discipline. Students' perception of achievement of goals was significantly and substantively related to perceptions of good teaching $(r=0.436, p=0.000)$, clear goals and standards $(r=0.409, p=0.000)$ and deep approaches to study $(r=0.355, p=0.000)$.

The strongest and most substantive relationship was found between students' perception of achievement of goals and their perceived understanding of the discipline $(r=0.499, p=0.000)$. The relationship between difficulty of transition and understanding of the discipline was 
Table 3 Correlations between transition, induction, goals, CEQ and SPQ

\begin{tabular}{lccc}
\hline Dimension & Transition $(p$ value $)$ & Induction $(p$ value $)$ & Goals $(p$ value $)$ \\
\hline Good teaching & $0.043(0.173)$ & $0.381(0.000)$ & $0.436(0.000)$ \\
Clear goals and standards & $-0.070(0.028)$ & $0.387(0.000)$ & $0.409(0.000)$ \\
Appropriate assessment & $-0.065(0.040)$ & $0.015(0.625)$ & $-0.014(0.497)$ \\
Appropriate workload & $-0.262(0.000)$ & $0.070(0.027)$ & $0.112(0.002)$ \\
Deep approaches & $0.124(0.000)$ & $0.309(0.000)$ & $0.355(0.000)$ \\
Surface approaches & $0.124(0.000)$ & $0.141(0.000)$ & $0.151(0.000)$ \\
Goals & $0.094(0.003)$ & $0.499(0.000)$ & - \\
Induction & $0.234(0.000)$ & - & - \\
\hline
\end{tabular}

significant but not strong $(r=0.232, p=0.000)$, as was the relationship between difficulty of transition and achievement of goals which was negligible though statistically significant $(r=0.094, p=0.003)$.

\section{Discussion and conclusion}

Students play an important role in shaping the learning environment of their undergraduate experiences. How students perceive and respond to learning opportunities is valuable information for teachers and researchers committed to enhancing student learning outcomes (Biggs and Tang 2007; Ramsden 2003). As Hong Kong moves towards full implementation of the new 4-year undergraduate curriculum in 2012, of paramount importance is the acquisition of updated knowledge about how Hong Kong students experience their first year at university pertaining to school-university transition and induction into academic disciplines. In previous studies (Asmar et al. 2000; Lam and Kwan 1999; Lowe and Cook 2003), attention has been paid to issues of teaching and learning related to school-university differences, such as the approach to teaching, mode of learning, types of assessments and difficulty of course content. These issues were used in this study to create a scale on perceived transition difficulties caused by such differences. Two other scales were reported in this paper, which were developed in this study. One of the two scales indicated students' perceptions of issues regarding their induction into the discipline during their first year, such as their understanding of the key concepts and theories learned, and skills and qualities developed as required in the profession. The other scale provided an indication of students' perceptions of their achievement of academic and personal goals during the first year. Validity and reliability estimates were demonstrated for these three scales.

From the data analysis, a few conclusions could be drawn in relation to the research questions. More than 50\% of students indicated having experienced transition difficulties in relation to differences in teaching and learning between school and university, with the most evident difficulties being the need to manage time and adapting to the approaches to teaching at university. However, despite such reported difficulties in relation to the transition issues, the relationships between the transition issues and the other areas of first-year experiences (induction into the discipline; achievement of goals) were not substantive $(r>$ 0.3). From this observation, we concluded that although students experienced difficulties caused by differences in teaching and learning between school and university, such difficulties were not related to their perceptions of the course and approaches to study. This suggests that in promoting a better learning experience for students and foster among them deeper approaches to study, the schooluniversity differences would be worthy of note, but may not constitute the major areas for improving students' firstyear experience.

When we looked at the relationships between students' understanding of the discipline and other learning experiences, we identified significant and substantive results. Students who felt that they had a good understanding of their discipline were those who perceived the teaching to be good $(r=0.381, p=0.000)$ and the goals and standards of the course to be clear $(r=0.387, p=0.000)$. They were also the students who indicated deeper approaches to study ( $r=0.326, p=0.000$ ). This was a significant finding which indicated that focusing on promoting a better learning environment for students would be a promising direction in facilitating students' induction into their disciplinary area. Although not surprising, these findings were also true with student's perceptions of achievement of goals. Students who felt they had achieved their goals were those who perceived the teaching to be good $(r=0.436$, $p=0.000)$ and the goals of the course to be clear $(r=0.409, p=0.000)$. They were also the students who indicated deeper approaches to study $(r=0.355, p=$ 0.000 ). These results suggested that for many students achieving their goals played a significant part in having a conducive first-year learning experience and that more effective learning environment tended to foster students' deep study approaches and assist their goal achievement. 
It is important that students are sufficiently inducted into the discipline and have a sense of achievement of academic and personal goals. In this study, students' perceptions of the difficulties caused by the differences in teaching and learning between school and university did not relate to either of these two aspects of first-year experience. These results were not causal, but were sufficient to suggest that improvement in perceptions of transition might not necessarily translate into better understanding of discipline area or achievement of goals. What the results did show us was that achievement of goals and understanding of the discipline were strongly associated $(r=0.499, p=0.0$ 00). Previous research evidence from Western literature suggests that the extent to which the institutional environment supports students' achievement of personal and academic goals (i.e. congruence between students' goals and institutional academic and social cultures) and students' sense of being integrated into the academic and social communities at university are highly associated with students' intention to complete their education programme (i.e. retention in higher education) (Yorke and Longden 2007; Tinto 1993). Similar findings were reported in a Hong Kong study (Zeng and Watkins 2010), in which Chinese students' commitment to their educational programme was found to depend on the extent to which they felt integrated into faculty communities and satisfied with their academic development (see also Kember et al. 1991). By revealing a strong correlation between achievement of goals and academic induction, our findings extend the existing research into the relationship between academic and social integration and retention in higher education.

To sum up, the findings suggest that with the Chinese students in this study generally reported difficulties in adapting to learning at university during their first year of undergraduate education. The extent to which these students were able to overcome transition difficulties, become inducted into their academic discipline and achieve their learning and personal goals was dependent on the extent to which they were provided with a supportive teaching and learning environment. These findings indicated that whereas first-year undergraduate students are increasingly encouraged and required to share responsibilities for their undergraduate education, the task shouldered by their institution and teachers to enable students to become autonomous learners would be no less demanding. In fulfilling such task, attention needs to be paid to the construction of an effective learning environment and cultivating climate for all students (Biggs and Tang 2007; McInnis 2001; Ramsden 2003), while taking into consideration students' prior learning experiences, personal preferences in learning and their learning culture such as the Confucian learning culture prominent among East Asian and South-East Asian students (Kember 2000; Watkins and Biggs 2001a).

Context relevance of the measurements contributed to the strength of this study. We used both the CEQ and the SPQ that are widely cited in the literature and used in various contexts including Asian cultures. We also incorporated three new measurements on academic transition, academic induction and goal achievement, which we developed by examining themes arising from the literature and focus groups conducted at the university under investigation. These ensured that all the measurements were relevant to the learning environment at the university in question. We would not claim to generalize the findings to first-year student at the other institutions in Hong Kong, but rather the study was initial research conducted to investigate the issues. Having established the measurements' validity, reliability and capacity to generate required information on first-year experience, a sensible next step in further research would be administering the questionnaires to other institutions in Hong Kong and further validating its applicability to the local context. Researchers can also examine issues identified in this study with qualitative methodologies to provide more granulated information on the issues. Future research in these directions would potentially generate meaningful information on these issues in the wider Hong Kong context. In doing so, cultural relevance of the firstyear experience studies should be maintained by paying attention to the influences of the Confucian cultural heritage on students' learning.

The most significant finding from this study was that students who had a good understanding of their discipline and achieved their goals were also those who perceived the teaching to be good, the goals and standards of courses to be clear and who were adopting deeper approaches to study. By reporting on students' perception on their academic transition and induction and goal achievement experiences at university, this study sheds new light on issues relating to student retention and success as well. Even though retention and student grades were not directly addressed in the study, the findings were highly relevant to such underlying issues of retention, such as goal achievement and academic integration. Further research into student retention may look into these aspects of student experience, which might yield interesting findings. Since this study did not investigate the causal nature of such relationship, further research would be necessary for providing extended evidence related to this finding.

Open Access This article is distributed under the terms of the Creative Commons Attribution Noncommercial License which permits any noncommercial use, distribution, and reproduction in any medium, provided the original author(s) and source are credited. 


\section{References}

Asmar, C., Brew, A., McCulloch, M., Peseta, T., \& Barrie, S. (2000). Report on the first year experience project. Sydney: Institute for Teaching and Learning, The University of Sydney.

Astin, A. W. (1993). What matters in college? Four critical years revisited. San Francisco, CA: Jossey-Bass Inc.

Biggs, J. (1987). The study process questionnaire (SPQ) users' manual. Hawthorne, Victoria: Australian Council for Educational Research.

Biggs, J., Kember, D., \& Leung, D. Y. P. (2001). The revised twofactor study process questionnaire: R-SPQ-2F. British Journal of Educational Psychology, 71, 133-149.

Biggs, J., \& Tang, C. (2007). Teaching for quality learning (3rd ed.). Buckingham: Society for Research into Higher Education and Open University Press.

Bond, R., \& Smith, P. B. (1996). Culture and conformity: A metaanalysis of studies Using Asch's (1952b, 1956) line judgment task. Psychological Bulletin, 119(1), 111-137.

Chalmers, D., \& Volet, S. (1997). Common misconceptions about students from South-East Asia studying in Australia. Higher Education Research \& Development, 16(1), 87-99.

Chan, C. (2008). Pedagogical transformation and knowledge-building for the Chinese learner. Evaluation \& Research in Education, $21(3), 235-251$

Coates, H. (2005). The value of student engagement for higher education quality assurance. Quality in Higher Education, 11(1), 25-36. doi:10.1080/13538320500074915.

Crawford, K., Gordon, S., Nicholas, J., \& Prosser, M. (1998). Qualitatively different experiences of learning mathematics at university. Learning and Instruction, 4(5), 331-345. doi:10.10 16/S0959-4752(98)00005-X.

Davies, H., Sivan, A., \& Kember, D. (1994). Helping Hong Kong business students to appreciate how they learn. Higher Education, 27(3), 367-378.

Entwistle, N., \& Trait, H. (1995). Approaches to studying and perceptions of the learning environment across disciplines. In $\mathrm{N}$. Hativa \& M. Marincovich (Eds.), Disciplinary differences in teaching and learning: Implications for practice (pp. 93-104). San Francisco: Jossey-Bass Publications.

Falchikov, N., \& Boud, D. (2007). Assessment and emotion: The impact of being assessed. In D. Boud \& N. Falchikov (Eds.), Rethinking assessment in higher education (pp. 144-156). London: Routledge.

Finkelstein, M. J., \& Walker, E. M. (2008). The progress of Hong Kong's universities in implementing the 3-3-4 reforms: A status report on preparation and prospects. Hong Kong: The University of Hong Kong.

Ginns, P., Prosser, M., \& Barrie, S. (2007). Students' perceptions of teaching quality in higher education: The perspective of currently enrolled students. Studies in Higher Education, 32(5), 603-615. doi:10.1080/03075070701573773.

Gow, L., \& Kember, D. (1990). Does higher education promote independent learning? Higher Education, 19(3), 307-322. doi: 10.1007/BF00133895.

Harvey, L., Drew, S., \& Smith, M. (2006). The first year experience: A literature review for the Higher Education Academy. York: Higher Education Academy.

Kember, D. (2000). Misconceptions about the learning approaches, motivation and study practices of Asian students. Higher Education, 40(1), 99-121. doi:10.1023/A:1004036826490.

Kember, D., \& Gow, L. (1991). A challenge to the anecdotal stereotype of the Asian student. Studies in Higher Education, 16(2), 117-128. doi:10.1080/03075079112331382934.
Kember, D., Lee, K., \& Li, N. (2001). Cultivating a sense of belonging in part-time students. International Journal of Lifelong Education, 20(4), 326-341. doi:10.1080/02601370117754.

Kember, D., Murphy, D., Siaw, I., \& Yuen, K. S. (1991). Towards a causal model of student progress in distance education: Research in Hong Kong. American Journal of Distance Education, 5(2), 3-15.

Krause, K., Hartley, R., James, R., \& McInnis, C. (2005). The first year experience in Australian universities: Findings from a decade of national studies. Retrieved August 10, 2007, from http://www.griffith.edu.au/centre/gihe/aboutus/klk_publications/ FYEReport05.pdf.

Lam, B. H., \& Kwan, K. P. (1999). Student expectations of university education. In J. Jones \& K. P. Kwan (Eds.), Evaluation of the student experience project (Vol. 3, pp. 11-20). Hong Kong: Center for the Enhancement of Learning and Teaching, City University of Hong Kong.

Li, J. (2002). A cultural model of learning: Chinese "heart and mind for wanting to learn". Journal of Cross-cultural Psychology, $33(3), 248-269$.

Lowe, H., \& Cook, A. (2003). Mind the gap: Are students prepared for higher education? Journal of Further and Higher Education, 27(1), 53-76.

McInnis, C. (2001). Researching the first year experience: Where to from here? Higher Education Research and Development, 20(2), $105-114$.

McInnis, C., Griffin, P., James, R., \& Coates, H. (2001). Development of the course experience questionnaire (CEQ). Melbourne: University of Melbourne.

McInnis, C., James, R., \& McNaught, C. (1995). First year on campus: Diversity in the initial experiences of Australian undergraduates. Canberra: Australian Government Publishing Services.

Pascarella, E. T., \& Terenzini, P. T. (2005). How college affects students: A third decade of research (Vol. 2). Indianapolis, IN: Jossey-Bass.

Pitkethly, A., \& Prosser, M. (2001). The first year experience project: A model for university-wide change. Higher Education Research \& Development, 20, 185-198. doi:10.1080/758483470.

Prosser, M., \& Trigwell, K. (1999). Understanding learning and teaching: The experience in higher education. Philadelphia: Open University Press.

Ramsden, P. (1991). A performance indicator of teaching quality in higher education: The course experience questionnaire. Studies in Higher Education, 16(2), 129-150. doi:10.1080/0307507911 2331382944.

Ramsden, P. (2003). Learning to teach in higher education (2nd ed.). London: Routledge.

Ratcliff, J. L. (1997). What is a curriculum and what should it be? In J. G. Gaff \& J. L. Ratcliff (Eds.), Handbook of the undergraduate curriculum: A comprehensive guide to purposes, structures, practices, and changes (pp. 5-29). San Francisco: Jossey-Bass.

Salili, F. (2001). Teacher-student interaction: Attributional implications and effectiveness of teachers' evaluative feedback. In D. Watkins \& J. Bigges (Eds.), Teaching the Chinese learner: Psychological and pedagogical perspectives (pp. 77-98). Hong Kong: Comparative Education Research Centre, The University of Hong Kong.

Stark, J. S., \& Lattuca, L. R. (1996). Shaping the college curriculum: Academic plans in action. Needham Heights, MA: Allyn \& Bacon.

Tang, C. (1996). Collaborative learning: The latent dimension in Chinese students' learning. In D. Watkins \& J. Biggs (Eds.), The Chinese learner: Cultural, psychological and contextual influences. Hong Kong: Comparative Education Research Centre, The University of Hong Kong. 
Terenzini, P., Rendon, L., Lee Upcraft, M., Millar, S., Allison, K., Gregg, P., et al. (1994). The transition to college: Diverse students, diverse stories. Research in Higher Education, 35(1), 57-73. doi:10.1007/BF02496662.

Tinto, V. (1993). Leaving college: Rethinking the causes and cures of student attrition (2nd ed.). Chicago: University of Chicago Press.

Tinto, V. (1997). Classrooms as communities: Exploring the educational character of student persistence. The Journal of Higher Education, 68(6), 599-623.

Watkins, D., \& Biggs, J. (2001a). The paradox of the Chinese learning and beyond. In D. Watkins \& J. Biggs (Eds.), Teaching the Chinese learner: Psychological and pedagogical perspectives. Hong Kong: Comparative Education Research Centre, The University of Hong Kong.

Watkins, D., \& Biggs, J. (2001b). Teaching the Chinese learner: Psychological and pedagogical perspectives. Hong Kong:
Comparative Education Research Centre, The University of Hong Kong.

Yorke, M., \& Longden, B. (2007). The first year experience in higher education in the UK. Heslingon, UK: The Higher Education Academy.

Zeng, M., \& Watkins, D. (2010). Adaptation of Mainland postgraduate students to the Hong Kong's universities. In D. W. Chapman, W. K. Cummings, \& G. A. Postiglione (Eds.), Crossing borders in East Asian higher education. Hong Kong: Comparative Education Research Centre.

Zhang, L. F., \& Watkins, D. (2001). Cognitive development and student approaches to learning: An investigation of Perry's theory with Chinese and U.S. university students. Higher Education, 41(3), 239-261. 